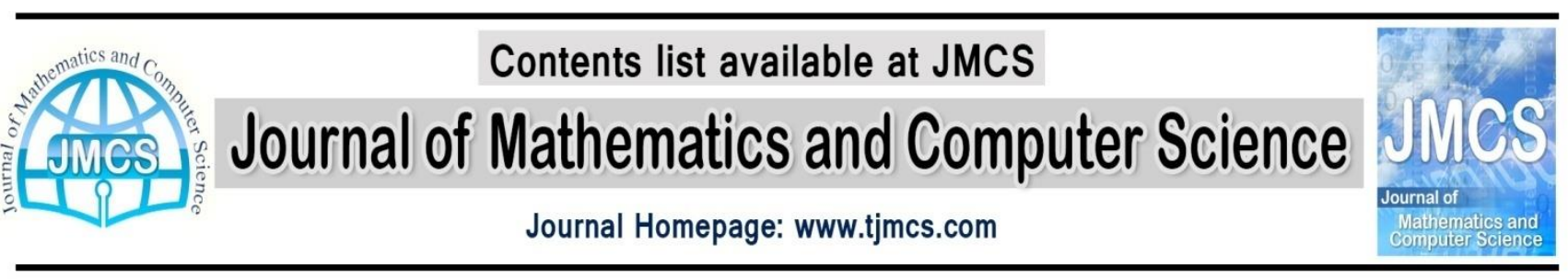

\title{
Software Trustworthy Testing Based on Cloud Testing
}

\author{
A. Mohsenzadeh ${ }^{1}$ \\ ${ }^{1}$ Department of Information Technology, Mazandaran University of Science and Technology, Babol, Iran \\ a.mohsenzadeh@ustmb.ac.ir
}

Article history:

Received 5, November 2014

Accepted 1, January 2015

Available online 8, January 2015

\begin{abstract}
Testing becomes an important process in software development not only in terms of exposure but also in terms of performance, usability, safety, security, reusability. Also software testing is an essential activity to software quality assurance. Cloud testing is a method of software testing based on cloud computing that offers testing as a service To test the SaaS, NonSaaS, service application over clouds and clouds. To test the cloud-based software and applications, tools and techniques are needed to address concerns of the cloud infrastructure such as dynamic configuration. This paper provides a comprehensive assessment on cloud testing. It analyzed the questions raised by managers, tester and engineers, and it offers clear concepts, discusses the specific objectives, advantages, features and requirements, in cloud computing testing. Also, it offers a comparative view between cloud-based application testing and conventional software testing as well as the comparison between commercial testing tools and examines the advantages in testing cloud-based software applications.
\end{abstract}

Keywords: Cloud computing, cloud testing, conventional software testing.

\section{Introduction}

Testing is the key to reduce the costs and increase users satisfaction. On the other hand, organizations needs to funds a lot in order to get a license and providing experts, tools and environment needed for test, but should be considered the quality can never be compromised. A new method of testing make the organizations to ensure higher quality but with lower funds [1].Hence the need to cloud emerged with a solution for reduce costs and helps organizations to focus on their core business.

Cloud computing brings new business opportunities, and causes some major impacts on software testing [2].Testing as a Service (TaaS), is the most important services offered in the cloud testing. TaaS is considered as a new business and service model, in which a provider undertakes software testing activities in a cloud for users as a service based on their demands. Cloud testing is still new subject in software 
testing community. Therefore, test engineers and quality assurance managers encountered many challenges in testing software, clouds and cloud-based applications.

The next section discusses cloud testing concepts, including definitions, objectives, facts and types. Section 3 is devoted to the discussion about Advantages and disadvantages of cloud testing. Section 4 examines the features offered in the cloud computing testing. Section 5 discusses differences between cloud testing and conventional software testing. Section 6 reviews cloud testing tools. Finally, the conclusion remarks are given in Section 7.The text must be in English. Authors whose English language is not their own are certainly requested to have their manuscripts checked (or co-authored) by an English native speaker, for linguistic correctness before submission and in its final version, if changes had been made to the initial version. The submitted typeset scripts of each contribution must be in their final form and of good appearance because they will be printed directly. The document you are reading is written in the format that should be used in your paper.

\section{What is Cloud Testing}

There are some definitions about cloud testing, As follows:

- According to https://sw.thecsiac.com Cloud Testing or more formally, Cloud Computing Testing, is a form of software testing in which web applications use cloud computing environments to facilitate the tests.

- Cloud computing Testing is testing cloud-based applications that use resources found in the cloud such as software, hardware, platform and infrastructure and any element necessary to carry out the tests [3].

- Concepts of cloud testing, cloud and SaaS are aligned, thereby cloud testing bringing the same advantages that the cloud brings to users, by providing the ability to test with leveraging the cloud $[4,2]$.

- According to Wikipedia, Cloud testing is a form of software testing in which software and web applications use cloud computing environments (a "cloud") to simulate real-world user traffic and the types of testing that can support include: stress testing, performance testing, load testing, functional testing, compatibility testing, browser performance testing, latency testing.

In summary, cloud testing refers to testing and measurement activities on a cloud infrastructure and environment by leveraging cloud solutions and technologies. It has three objectives that is listed below:

- To ensure the quality of cloud-based applications that is deployed in a cloud, such as their system performance and scalability, functional services, business processes.

- To validate and verify software as a service and non-software as a service in a cloud environment, such as software performance, security, functionality, reusability, scalability, and measurement based on pre-defined SLAs.

- To test cloud such as cloud compatibility and communication between SaaS and applications in a cloud infrastructure.

\section{1 facts of Cloud Testing}

There are four different facts of cloud-based software testing. Each of them has different objectives and focuses. 
1) Testing a SaaS or non-SaaS in a cloud - It makes sure the quality of a SaaS or non-SaaS based on its non-functional and functional service requirements. Also, this includes testing at different test such as security testing, ...

2) Testing Within a cloud - It surveys the quality of a cloud based on cloud capabilities and the internal infrastructures of a cloud .This type of testing is done on all models of cloud i.e. private, public and hybrid clouds. Since only Cloud vendors have access to internal infrastructure, they can do this kind of testing. [5,6].

3) Testing of a cloud - Cloud environments should be tested. Also to support delivery of services, cloud environments availability, performance, scalability and security should be measured $[5,6]$.

4) Testing over cloud - This type of test is performed by application providers. It tests service application over clouds i.e. private, public, and hybrid clouds based on application service requirements [2].

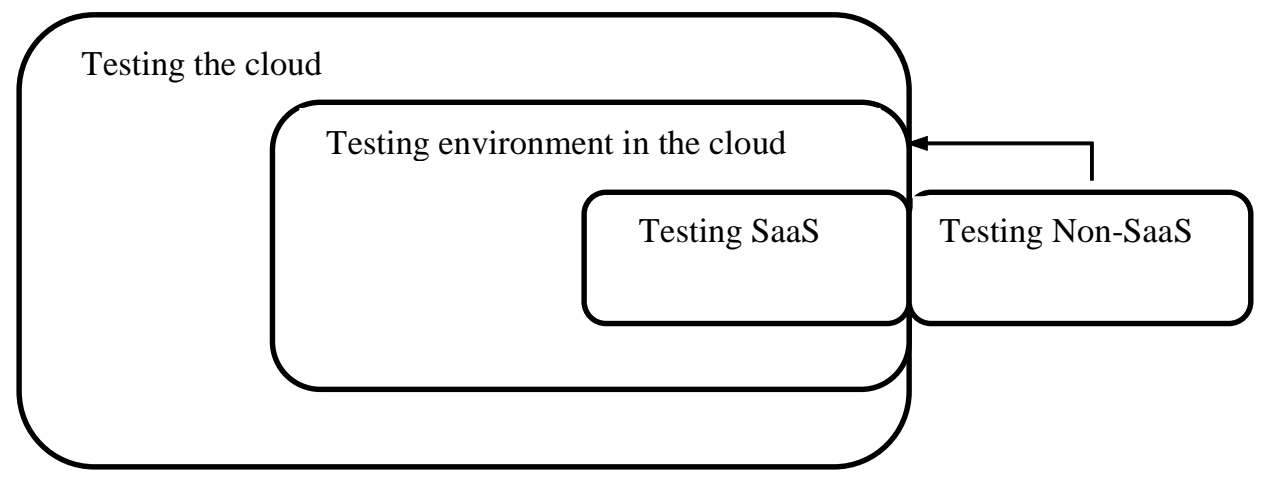

Figure1. Facets of Cloud testing

\section{2 three types of cloud testing that is practiced in the industry}

- Cloud/SaaS-oriented testing: This type of testing is actually testing the cloud, that is done by engineers vendors and its objective is to ensure the quality of the provided service in a cloud. Tests that may be done in this type include: unit testing, integration testing, system testing, regression testing, performance, scalability evaluation testing, functional testing and security testing $[2,3,6]$.

- Online-based application testing: This type of testing is actually testing using cloud, that is done by online application vendors In order to conduct online-based system function testing and performance evaluation by using with cloud-based traffic and user accesses. Therefore online application vendors will not require in-house test laboratory $[3,6]$.

- Cloud-based application testing over clouds: This type of testing refers to the activities performed to ensure the quality of a cloud-based application crossing different clouds. Unlike the previous two types, this type of testing is actually In order to assure the quality of the end-to-end application over clouds. [2].

\section{3. cloud testing advantages, disadvantages}

This section, first discusses cloud testing advantages and then express primary issues and Challenges in cloud testing. 


\subsection{Why is Cloud Testing Important?}

There are a number of advantages in testing clouds and cloud-based software which are listed below:

- Reduce costs by using virtualized resources (software and hardware) $[2,3,7,8]$. For example, rent the software testing platform in cloud computing is 4000000 Rial per month but buying the automated test software to spend at least 23000000 Rial per month.

- Another advantage is on-demand test services - This refers to effective real-time online validation for software (base on internet) in clouds.

- Readily leverage scalable cloud system infrastructure to test and evaluate system scalability and performance $[2,8]$.

-Improving the Testing Efficiency - by cloud testing, we can reduce the time to build a test environment, such as computer and network preparation, the operating system installation and installing software base on various testing tools.

- More realistic performance testing - by cloud testing You have access to more clients, Hence, You can better To simulate the performance of your software with more realistic scenarios [2].

-IBM reported the experience on cloud testing in small business division. This report shows that cloud testing provides the following advantages [9]:

- Shorten its licensing expenses and capital from $50 \%$ to $75 \%$ with using virtualized resources.

- Reduce operating costs from $30 \%$ to $50 \%$ by testing configuration and resource and automating development.

- Reduce development and setup time to minutes.

- Improve product quality from $15 \%$ to $30 \%$.

\subsection{Issues and Challenges in Cloud Testing}

There are a number of issues and challenges in testing clouds and cloud-based software, which are listed below:

- There are no standard solutions to integrate public cloud resources with users' internal data centers Each cloud provider has their own operating model, architecture and pricing mechanisms [3].

- Security is another major concern, because code and data may be stored in a remote location beyond an organization's legal and regulatory jurisdiction $[2,3,7,8]$. Here, there are a few questions:

- What security standard, techniques and protocol should be used in the cloud testing.

- How can we guarantee the security of cloud testing [10]?

- What techniques should be used for authorization and authentication [8] .

- Suitable range is limited in the cloud testing - In the cloud testing platform, Testing the B/S application software (such as website) is more suitable than the C/S structure [7].

- Creating a on demand test environment - Currently There is no support for creating a test environment based on testers needed [2,3,7]. 
- performance and Scalability testing - Issues such as scalable testing environments, cost-model, SLAbased requirements, frameworks, dynamic scalability, evaluation metrics and SLA-based requirements are not considered in the test cloud.

- Integration testing - Integration testing is done more costly and more difficult in the Cloud. Because, engineers must deal with integration of different applications and SaaS based on connectivity protocols and their provided APIs .

\section{4. features offered in the cloud computing testing}

Cloud Testing offers a suite of services that allow website managers, testers, developers, to speed up, automate the testing and archiving of their websites using cloud platform[3]. A number of features are provided in the cloud computing testing are:

1-Instant test labs

2-Client and server parallelization

3-Testing as a service

4-On-demand workforce of testers

5-AMIs for refuse and reports

6-Web services for automation

7-...

Among the features and services listed, Testing as a Service (TaaS), is the most important services offered in the cloud testing. Therefore this feature (TaaS) will be discussed in this paper.

\subsection{TaaS: Testing as a Service}

There are several distinct features in cloud testing. TaaS is an innovative concept and is one of the most important services in cloud testing that reduces IT costs and budget of business [11] and it refers to providing dynamic/static on-demand testing services in/on/over clouds at any time [2,4]. The term TaaS today is an basic concept for consideration and study [12,13] and covers both the testing of cloud and testing using the cloud [14].

TaaS delivers application testing services in a highly available, pay-as-you-go model that provides flexibility in pricing and service. and helps you implement best practice quality management processes. [3].

According to Wikipedia, TaaS involves the on-demand test execution of well-defined suites of test material. The execution can be performed on client site or remotely from the outsourced providers test lab. According to http://www.tieto.com/, testing as a service (TaaS) was initially introduced as a concept by Tieto in Denmark in 2009. Nowadays TaaS significantly used due to its benefits such as cost reduction, on-demand testing services, scalable testing environment and utility-based service models.

As shown in figure.2 TaaS workflow includes the following:

- Access to the TaaS platform: Users can have access to TaaS platform Through the Internet $[1,2,6,11,15]$.

- TaaS process management: This process offers test process management

- Quality of Service requirements management: This process supports modeling of software testing including test cases and quality assurance modeling. 
- Access to services: Users can choose required services from the TaaS platforms service catalogue including:

- Test environment service: This service in order to establish the required virtual and physical cloud resources and infrastructures and tools [2].

- Test solution service: This service offers different solutions such as, test modeling and test methods.

- Test simulation service: this service creates test simulation environments

- On-demand test service: this service refer to on demand test execution based on a pre-defined service-level-agreement (SLA) and selected schedules [1,2,6].

- Tracking and monitoring service: Through this service, tester can track and monitor program behavior

- TaaS pricing: At this phase the customer pays the cost of the test base on pre-defined service-levelagreement.

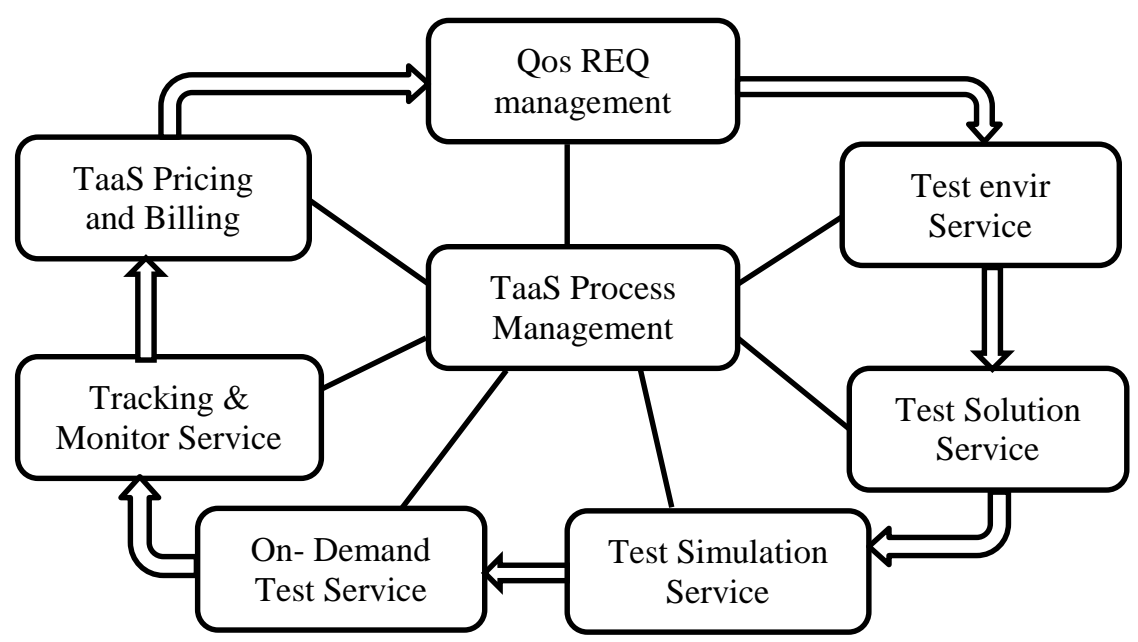

Figure2. The Workflow Of TaaS

\section{Cloud Testing Tools}

Cloud platform creates an infrastructure for service delivering, software hosting and resource sharing in a pay-per-use approach [23].To test the cloud-based software and applications, tools and techniques are needed to address concerns of the cloud infrastructure such as dynamic configuration. Also this tools can be created on the cloud platform in order to use from virtualized services and platform, Extensive resources, and parallelized execution.

There are a lot of cloud testing tools such as D-Cloud, PreFail, CloudSim, ETHZ, CloudTesting, SOASTA, iTKO, YCSB, Cloudstone, Testbed, YETI. But some of them are commercial testing tools, Therefore commercial testing tools will be discussed in this paper.

\subsection{SOASTA}

According to http://www.SOASTA.com, SOASTA is the necessity to test in production, rather than in a laboratory environment. For example, Load testing with available tools in the laboratory can be very different from testing in the production environment in a number of fields such as configuration, scale, network environment and user profiles.

SOASTA CloudTest is a tool to produces performance testing and load testing for Web applications. It can simulate thousands of virtual users who are using websites simultaneously, with public or private cloud infrastructure service $[2,20,23]$. 
SOASTA provides three distributed services to support test creation, test execution and test results analysis. These distributed services are as follows:

- SOASTA Repository: This repository contains SOASTA CloudTest objects such as test scenarios, test composition, performance data and test clip. In fact, it is responsible for the delivery of these objects.

- Analytics Dashboard: The purpose of this service is to check and evaluate the results and analysis of data obtained from distributed load tests. It can also provide an environment, where correlates data streams from a distributed environment into a single one.

- Meastro: Maestro is a test engine as a multi-thread service, used for test execution such as validating responses, verifying answers and sending.

\subsection{ITKO LISA}

According to http://www.itko.com, ITKO LISA provides a cloud-based environment with virtual services for compound application development, verification and validation $(\mathrm{V} \& \mathrm{~V})$ and supports the simultaneous development and testing. Also, for Inaccessible or unavailable resources, ITKO provides virtualized services by simulating the system's dynamic conduct [2,23]. In fact ITKO architecture is established base on virtualization technology. LISA quality services is composed of 3 part :

1. LISA Test: Types of tests that are performed in this part include coverage-based testing, codeless testing, User Interface testing, performance testing and load testing. It also provides testability to all components in the cloud by LISA toolkit.

2. LISA Validate: LISA provides regression testing for each software build and in the production environment.

3. LISA Path finder: This part traces interactions and reviewing the data flow and control flow in a composite application. Hence, makes it easy for testers to localize defects and recognize bottlenecks through system execution process.

\subsection{Cloud Testing}

According to http://www.CloudTesting.com, It's purpose is to support and functional testing of web applications and cross browser. Cloud Testing provides a shared test environment, therefore users do not need to maintain and set up different testing platform to ensure website portability. Cloud Testing provides three testing services by using real browsers from the cloud that allow website managers, developers and testers to archiving of their websites, automate, speed up the testing [2]. These three services include: function testing, cross browser testing and website archiving

Table 1 compares three tools introduced above, based on following objectives:

- Testing Objective: Is composed of tests such as function testing, cost related testing, performance testing, scalability testing, fault tolerance testing and recovery testing.

- Testing activities: To develop test tools on a cloud, special activities are required, such as: test execution support, service mocking, scripting, test resource management, geographical simulation, test services, parallel execution, results aggregation. 
- Tool architecture: Number of cloud testing tools are not developed on the cloud platform. Those that are developed on the cloud platforms, testing with simulation support can improve cloud testability.

Table1: Comparison between cloud testing tools

\begin{tabular}{|c|c|c|c|}
\hline & Cloud Testing & ITKO & SOASTA \\
\hline \multicolumn{4}{|l|}{ Test Objective } \\
\hline function testing & Yes & yes & yes \\
\hline cost related testing & No & no & no \\
\hline performance testing & Yes & yes & yes \\
\hline scalability testing & No & no & no \\
\hline fault tolerance testing & No & no & no \\
\hline recovery testing & No & no & no \\
\hline \multicolumn{4}{|l|}{ Test Activity } \\
\hline test execution support & $\begin{array}{l}\text { grouped and multi browsers, } \\
\text { grouped scripting, scheduled } \\
\text { and manual }\end{array}$ & $\begin{array}{l}\text { regression and visual } \\
\text { scheduled test } \\
\text { execution }\end{array}$ & $\begin{array}{l}\text { manual and scheduled test } \\
\text { execution control }\end{array}$ \\
\hline service mocking & No & yes & no \\
\hline scripting & Supports of scripting & $\begin{array}{l}\text { code-less and } \\
\text { coverage test } \\
\text { generation }\end{array}$ & available except selenium \\
\hline $\begin{array}{l}\text { test resource } \\
\text { management }\end{array}$ & Yes & yes & yes \\
\hline geographical simulation & No & no & no \\
\hline test services & $\begin{array}{l}\text { function test service, cross } \\
\text { browser testing, website } \\
\text { archiving service }\end{array}$ & $\begin{array}{l}\text { Lisa test, Lisa } \\
\text { validate, Lisa path } \\
\text { finder }\end{array}$ & $\begin{array}{l}\text { cloudtest on-demand and } \\
\text { appliances, analytics } \\
\text { dashboard, Soasta } \\
\text { repository, Meastro }\end{array}$ \\
\hline parallel execution & No & yes & yes \\
\hline results aggregation & Yes & yes & yes \\
\hline \multicolumn{4}{|l|}{ Tool Architecture } \\
\hline scalability & No & no & no \\
\hline
\end{tabular}




\begin{tabular}{|c|c|c|c|}
\hline $\begin{array}{l}\text { architecture observer } \\
\text { ability }\end{array}$ & No & no & no \\
\hline cloud-based & Yes & yes & yes \\
\hline test methodology & $\begin{array}{l}\text { script-based execution and } \\
\text { script-based test development }\end{array}$ & $\begin{array}{l}\text { continuous validation } \\
\text { and collaborative test }\end{array}$ & $\begin{array}{l}\text { visual test creation, } \\
\text { and assembly }\end{array}$ \\
\hline $\begin{array}{l}\text { test monitoring and } \\
\text { virtualization }\end{array}$ & $\begin{array}{l}\text { crossing browser monitoring, } \\
\text { script-based test monitoring, } \\
\text { script report and monitor }\end{array}$ & $\begin{array}{l}\text { continuous validation } \\
\text { monitor }\end{array}$ & $\begin{array}{l}\text { agent-less and agent-based } \\
\text { approach, resource } \\
\text { monitoring }\end{array}$ \\
\hline
\end{tabular}

\section{Cloud Testing VS Conventional Software Testing}

According a [15] traditional software testing methodologies are based on best practices of testers. In traditional software testing, because of diversity the process content among the different corporate sectors, testers have to write a new proposal and design new test cases.

There are several factors that can affect on testing [16] These factors can be divided into two parts, first factors that have affects on testing and related procedures [17] such as Testing adjustment based on business procedure and policies, management complexity testing, software units testing, Testing based on risk and Interaction between design, implementation, development and testing. Second factors can affect other business venture and testing know-how.

In this section, first we compared software hosted in a cloud environment and in an in-house environment. Table 2 shows the details of this comparison. Then as shown in table 3, we compared the differences and similarities between Cloud-Based Software Testing that uses of a cloud environment and conventional software testing (specifically Internet-Based Software Testing i.e. Web-Based / Distributed System Infrastructure) That uses of an in- house environment $[1,2,18,19,20,21]$.

Table 2: Comparison Of Software In Cloud And In-House Environment

\begin{tabular}{|c|c|c|}
\hline & Cloud Hosting & In-house Hosting \\
\hline Architecture & $\begin{array}{l}\text { - Built-in distributed parallel computing } \\
\text { - High fault-tolerance }\end{array}$ & $\begin{array}{l}\text { - Centralized } \\
\text { - Parallel } \\
\text { - Fault tolerance }\end{array}$ \\
\hline Resource Allocation & $\begin{array}{l}\text { - Unlimited resource pools } \\
\text { - Dynamic allocation based on real-time usage }\end{array}$ & $\begin{array}{l}\text { - Stable dedicated resources } \\
\text { - Limited upper bound }\end{array}$ \\
\hline Configuration & $\begin{array}{l}\text { - Online deployment and reconfiguration } \\
\text { - Transparent to software providers }\end{array}$ & $\begin{array}{l}\text { - Pre-defined configuration } \\
\text { - Offline deployment }\end{array}$ \\
\hline $\begin{array}{l}\text { Runtime } \\
\text { Environment }\end{array}$ & $\begin{array}{l}\text { - Virtualized computing services } \\
\text { - Unpredictable environment } \\
\text { - Low controllability }\end{array}$ & $\begin{array}{l}\text { - Stable dedicated environment } \\
\text { - In-house control }\end{array}$ \\
\hline Resource Sharing & - Large scale resource sharing & - Limited sharing \\
\hline Scalability & $\begin{array}{l}\text { - Online massive scalability } \\
\text { - Dynamic scale up/down }\end{array}$ & - Offline scale up/down \\
\hline
\end{tabular}


Table 3: Comparison between cloud testing and conventional Software Testing

\begin{tabular}{|c|c|c|}
\hline & Cloud-Based Software Testing & Internet-Based Software Testing \\
\hline $\begin{array}{l}\text { Testing } \\
\text { Objectives }\end{array}$ & $\begin{array}{l}\text { - to ensure the quality of performance of SaaS, } \\
\text { Clouds, and applications by leveraging a cloud } \\
\text { environment }\end{array}$ & $\begin{array}{l}\text { - to ensure the quality of system } \\
\text { performance based on the given } \\
\text { specifications }\end{array}$ \\
\hline $\begin{array}{l}\text { Testing as a } \\
\text { Service }\end{array}$ & $\begin{array}{l}\text {-Real-time on-demand testing service and Online } \\
\text { testing service based on a pre-defined SLA }\end{array}$ & $\begin{array}{l}\text { - In-house software testing as engineering } \\
\text { tasks }\end{array}$ \\
\hline $\begin{array}{l}\text { Testing } \\
\text { Environment }\end{array}$ & $\begin{array}{l}\text { - cloud environment with diverse computing } \\
\text { resources }\end{array}$ & $\begin{array}{l}\text { - In-house test environment with } \\
\text { purchased software and hardware }\end{array}$ \\
\hline $\begin{array}{l}\text { Execution } \\
\text { Time }\end{array}$ & $\begin{array}{l}\text {-On-demand test execution by third-parties } \\
\text { - Online test execution in a public cloud; } \\
\text { - Offline test execution in a private cloud }\end{array}$ & $\begin{array}{l}\text { - Offline test execution in a test lab. and } \\
\text { Testing a product before its delivery }\end{array}$ \\
\hline $\begin{array}{l}\text { Test } \\
\text { Simulation }\end{array}$ & $\begin{array}{l}\text { - Simulated online/ virtual user access and traffic } \\
\text { data }\end{array}$ & $\begin{array}{l}\text { - Simulated online user access and traffic } \\
\text { data }\end{array}$ \\
\hline Testing Costs & $\begin{array}{l}\text { - TaaS and Cloud testing service, engineering } \\
\text { costs based on a pre-defined service-level- } \\
\text { agreement }\end{array}$ & $\begin{array}{l}\text { - hardware, software and license costs as } \\
\text { well as engineering costs }\end{array}$ \\
\hline $\begin{array}{l}\text { Scalability \& } \\
\text { Performance } \\
\text { Testing }\end{array}$ & $\begin{array}{l}\text { - Performed in a scalable test environment based } \\
\text { on a SLA } \\
\text { - Apply both virtual and real-time online test data }\end{array}$ & $\begin{array}{l}\text { - Performed a fixed test environment } \\
\text { - Apply simulated test data ,user access } \\
\text { and messages }\end{array}$ \\
\hline $\begin{array}{l}\text { Integration } \\
\text { Testing }\end{array}$ & $\begin{array}{l}\text { - SaaS , non SaaS integration in a cloud } \\
\text { - Application integration over clouds } \\
\text { - integration between Cloud/ SaaS and with } \\
\text { legacy systems }\end{array}$ & $\begin{array}{l}\text { - Function, component, architecture-based } \\
\text { integration and interface integration }\end{array}$ \\
\hline $\begin{array}{l}\text { Security } \\
\text { Testing }\end{array}$ & $\begin{array}{l}\text { - SaaS/Non SaaS/Cloud security } \\
\text { - application security over clouds } \\
\text { - SaaS/ Non SaaS /Cloud API and connectivity } \\
\text { security }\end{array}$ & $\begin{array}{l}\text { - Function-based security features } \\
\text { - User privacy } \\
\text { - Client/server and process access security }\end{array}$ \\
\hline
\end{tabular}




\section{Conclusion}

Cloud testing is becoming a hot research topic in software engineering community and software testing. Therefore, more research work must be done to address the challenges and open issues in cloud testing and TaaS. In this paper, we first introduced the definition of cloud testing then, we analyzed the questions of which software projects can be done by the cloud testing, why do clouds testing and how TaaS works. Also this paper offers a comprehensive review on cloud computing testing by discussing the related concepts, advantages and challenges. The main contributions of this paper include discussion about cloud computing testing and the comparison with conventional testing as well as the comparison between commercial testing tools.

\section{References}

[1] K. Priyadarsini, V. Balasubramanian, S. Karthik." Cloud Testing as a Service".(IJAEST) International Journal Of Advanced Engineering Sciences And Technologies Vol No. 6, Issue No. 2, 173 - 177

[2] Jerry Gao, Xiaoying Bai, and Wei-Tek Tsai. "Cloud Testing- Issues, Challenges, Needs and Practice". Software Engineering : An International Journal (SEIJ), Vol. 1, No. 1 (2011), SEPTEMBER

[3] Belatrix Software Factory, "testing service through cloud" (white paper)

[4] Leah Muthoni Riungu, Ossi Taipale, Kari Smolander, "Software Testing as an Online Service: Observations from Practice," In Third International Conference on Software Testing, Verification, and Validation Workshops (ICSTW), 418-423 (2010).

[5] A. Lenk, M. Klems, J. Nimis, S. Tai, and T. Sandholm, "What's in the Cloud: An Architectural Map of the Cloud Landscape", In Proc.Cloud Computing Workshop, International Conference on Software Engineering, 2009, pp. 23-31, doi: 10.1109 /CLOUD .(2009).5071529

[6] Neha Mehrotra ,"Cloud-Testing Vs.Testing A Cloud", 10th Annual International Software Testing Conference (2010)

[7] Wang Jun, Fanpeng Meng ." Software Testing Based on Cloud Computing" International Conference on Internet Computing and Information Services (2011).

[8] AppLabs,"Testing the Cloud,"white paper,Internet: www.applabs.com/html/Testing the Cloud 786 .html

[9] P. Jogalekar, M. Woodside. "Evaluating the scalability of distributed systems", IEEE Trans. Parallel and Distributed Systems, vol. 11,no. 6, 589-603, 2000

[10] B. Wrenn, CISSP, ISSEP, "Unisys Secure Cloud Addressing the Top Threats of Cloud Computing", (white paper).

[11] P. Williams, "Value versus cost: governing IT on a reduced budget", ComputerWeekly.com, Friday 08, February (2002).

[12] Lian Yu, Wei-Tek Tsai, Xiangi Chen, Linqing Liu, Yan Zhao,Liangjie Tang, Wei Zhao. "Testing as a Service over Cloud," In the Fifth IEEE International Symposium on Service Oriented System Engineering, (2010).

[13] G.Candea, S.Bucur, and C.Zamfir "Automated software testing as service" proceeding of the 1st Symposium On Cloud Computing(SOCC 10), June 10-11, (2010), Indianapolis, Indiana USA .

[14] sonata software," testing cloud and testing using cloud" (2011), 11 july

[15] Kitchenham, B. A., Pfleeger, S. L., Pickard, L. M., Jones, P. W., Hoaglin, D. C., Emam, K. E., Rosenberg, "J.Preliminary Guidelines for Empirical Research in Software Engineering", IEEE Transactions on Software Engineering,28, No. 8 (2002), 721-733

[16] Taipale, O., Smolander, K., Kälviäinen, H. “Cost Reduction and Quality Improvement in Software Testing”, In Software Quality Management Conference, Southampton, UK, (2006).

[17] Atif Farid Mohammada, Hamid Mcheickb. "Cloud Services Testing: An Understanding", The 2nd International Conference on Ambient Systems, Networks and Technologies (ANT)

[18] R. Collard, "Performance innovations, testing implications", Software Test \& Performance Magazine, Vol. 6, No. 8 (2009), 19-20, August.

[19] A.Y. Grama, A. Gupta, V. Kumar, Isoefficiency: "Measuring the Scalability of Parallel Algorithms and Architectures", IEEE Parallel and Distributed Technology, 12-21, Aug. (1993).

[20] Neha Thakur," Performance Testing In Cloud":White Paper Submitted For Stc (2010)

[21] Li Zhang, Yinghui Chen, Fan Tang, Xiong Ao " Design And Implementation Of Cloud-Based Performance Testing System For Web Services", $6^{\text {th }}$ International Icst Conference On Communications And Networking In China (Chinacom) (2011).

[22] Jerry Gao, Xiaoying Bai, Wei-Tek Tsai. "Cloud Testing- Issues, Challenges, Needs and Practice". Software Engineering : An International Journal (SEIJ), Vol. 1, No. 1 (2011), SEPTEMBER.

[23] Xiaoying Bai, Muyang Li, Bin Chen, Wei-Tek Tsai, Jerry Gao. "Cloud Testing Tools", Proceedings of The $6^{\text {th }}$ IEEE International Symposium on Service Oriented System Engineering (SOSE 2011). 